\title{
POLÍTICA DE FORMAÇÃO DOS PROFESSORES DO CAMPO: PRÁTICA DE RESISTÊNCIA NA AMAZÔNIA ${ }^{1}$
}

\author{
Hellen do Socorro de Araújo Silva² \\ Carlos Nazareno Ferreira Borges ${ }^{3}$ \\ Maria do Socorro Dias Pinheiro ${ }^{4}$
}

\begin{abstract}
Resumo
O texto objetiva analisar a política de formação dos professores do campo e sua contribuição para construção da escola do campo como prática de resistência no território da Amazônia paraense. A metodologia se ancorou em estudos bibliográficos, documentais e pesquisa de campo. Os resultados evidenciaram que a formação de professores tem pautado estudos e debates que corroboram para refletir a escola do campo, suas contradições, seus desafios e as possibilidades de transformações por meio de práticas de resistências.
\end{abstract}

Palavras-chave: Políticas Educacionais; Educação do Campo; Licenciatura em Educação do Campo.

\section{POLÍTICA DE FORMACIÓN DE PROFESORES DEL CAMPO: PRÁCTICA DE RESISTENCIA EN LA AMAZÔNIA}

\section{Resumen}

El texto tiene como objetivo analizar la política de capacitación de docentes rurales y su contribución a la construcción de escuelas rurales como práctica de resistencia en el territorio de la Amazonía de Pará. La metodología se basó en estudios bibliográficos, documentales e investigaciones de campo. Los resultados mostraron que la capacitación de maestros ha guiado los estudios y debates que corroboran para reflejar la escuela rural, sus contradicciones, sus desafíos y las posibilidades de cambios a través de las prácticas de resistencia.

Palabras clave: Políticas educativas; Educación rural; Grado en Educación Rural.

\section{POLICY FOR TRAINING COUNTRY TEACHERS: PRACTICE DE RESISTANCE IN THE AMAZON}

\section{Abstract}

The text aims to analyze the training policy of countryside teachers and their contribution to the construction of countryside school as a practice of resistance in the territory of the paraense Amazon. The methodology was anchored in bibliographic and documentary studies, and field research. The results showed that the training of countryside teachers has guided studies and debates that corroborate to reflect the countryside school, its contradictions, its challenges and the possibilities of changes through resistance practices.

Keywords: Educational Policies; Country Education; Degree in Country Education

\footnotetext{
${ }^{1}$ Artigo recebido em 20/04/2020. Primeira avaliação em 31/05/2020. Segunda avaliação em 30/06/2020. Terceira avaliação em 15/07/2020. Aprovado em 04/08/2020. Publicado em 25/09/2020. DOI: https://doi.org/10.22409/TN.V18I37.42429

2 Doutora em Educação pela Universidade Federal do Pará. Docente da Universidade Federal do Pará do Programa de Pós-Graduação em Educação e Cultura/ PROCAD/Amazônia - Brasil. E-mail: hellen.ufpa@gmail.com ORCID: 0000-0002-5443-2373. Lattes: http://lattes.cnpq.br/4932105074922888

3 Doutor em Educação Física pela Universidade Gama Filho - Rio de Janeiro - Brasil. Docente Associado da Universidade Federal do Pará - Brasil, do Programa de Pós-Graduação em Educação. E-mail: naza_para@yahoo.com.br. ORCID: 0000-0002-1908-3315.

Lattes: http://lattes.cnpq.br/2548063126332942

4 Doutoranda do Programa de Pós-Graduação em Educação e Mestre em Educação pela Universidade Federal do Pará (UFPA) - Brasil.. Docente da Universidade Federal do Pará (UFPA) - Brasil

E-mail: sdiasufpa2@gmail.com ORCID: 0000-0003-1109-6733.

Lattes: http://lattes.cnpq.br/7850316457132758
} 


\section{Introdução}

A política direcionada para formar professores do campo no Brasil e na Amazônia tem sido, neste século XXI, o epicentro do debate pelo (des) interesse por parte do projeto político instalado no Brasil. A referida política se fundamenta na lógica privado-mercantil e no rentismo, que ganha força com a crise orgânica do capitalismo de 2008 e se manifesta de diversas formas em todos os países (MANCEBO, 2019). A autora diz também que no Brasil, tal crise acirrou as desigualdades sociais e econômicas, afetando ainda os alicerces políticos, sobretudo após o impeachment da presidenta Dilma Rousseff em 2016, que conduziu ao cargo de presidente da República Michel Temer.

As primeiras medidas tomadas pelo governo de Michel Temer estiveram concentradas em reformas que procuraram reduzir os gastos com saúde e educação, o que se agravou com a Proposta de Emenda Constitucional (PEC) ํo 55 de 2016, cujo objetivo foi restringir os gastos sociais por 20 anos. Estas medidas limitam a efetivação do Plano Nacional de Educação (Lei 13.005/2014) em determinadas metas, dentre as quais podemos mencionar: o cumprimento no atendimento de educação obrigatória de 4 a 17 anos; a valorização dos profissionais da educação; além dos cortes nos investimentos para as universidades públicas.

Hage, Silva e Souza (2019) afirmam que o pleito ocorrido em 2018, ao eleger como presidente Jair Bolsonaro, coloca em pauta a lógica do projeto conservador da ultradireita. Este projeto tem intensificado o desmonte dos direitos trabalhistas conquistados pela Consolidação das Leis do Trabalho (CLT) e o acesso aos direitos sociais previstos na Constituição de 1988. Os autores dizem ainda que houve a implementação de políticas de austeridade, que impõem o controle e diminuição dos investimentos públicos nas políticas sociais e educacionais.

Os impactos das ações do atual governo têm ocasionado uma sensação de incerteza na política educacional brasileira, principalmente na política de formação dos professores do campo. Por exemplo, a institucionalidade dos cursos de Licenciatura em Educação do Campo (LEDOC) enfrenta sérios riscos de perda de sua identidade.

Em que pese as Instituições de Educação Superior (IES) públicas assumirem os mencionados cursos como política permanente, enfrentam os cortes em seu financiamento, sendo que consideramos os recursos como essenciais para o 
funcionamento desta modalidade de licenciatura. Entre os recursos seriamente comprometidos com os cortes ocasionados pela atual política de governo estão os destinados para aquisição de material didático; alimentação e moradia dos estudantes; e às atividades do 'tempo comunidade' e 'trabalho de campo'. ${ }^{5}$

A Organização Não Governamental 'Ação Educativa', juntamente com o portal virtual 'De Olho nos Planos' e o coletivo 'Carta Educação' elaboraram um material que traz reflexões sobre os 100 dias do atual presidente em 2019. Este material apresenta as correlações de força e os projetos educacionais em disputa, visto que há um desmonte das secretarias, programas e projetos no âmbito do Ministério da Educação (MEC). Entre as evidências do desmonte, destacamos a dissolução da Secretaria de Educação Continuada, Alfabetização, Diversidade e Inclusão (SECADI); e extinção da Secretaria de Articulação com o Sistema de Ensino (SASE), criada em 2011 para acompanhar o processo de monitoramento e avaliação dos planos estaduais e municipais de educação.

No campo da Política Agrária, destacamos a aprovação do Decreto 10.252 de 21 de fevereiro de 2020, que apresenta alterações estruturais e regimentais do Instituto Nacional de Colonização e Reforma Agrária (INCRA). A partir de então, toda a política agrária fica subordinada à formulação do Ministério da Agricultura, Pecuária e Abastecimento (MAPA). Houve também a extinção de coordenações no INCRA, dentre as quais registramos a Coordenação-Geral de Educação do Campo e Cidadania, setor responsável pelo Programa Nacional de Educação na Reforma Agrária (PRONERA). Isto representa a retirada de direitos dos povos tradicionais e camponeses, conquistados por mais de 20 anos de luta.

Diante de medidas que desconsideram a educação como um direito de todos, o MEC apresenta um conjunto de projetos centrados numa visão que secundariza a concepção historicamente acumulada e referenciada pela luta dos trabalhadores do campo e da cidade.

$\mathrm{Na}$ perspectiva de contrastar com os saberes sociais, culturais, políticos, econômicos e formativos de caráter inclusivo, o MEC lança projetos e resoluções que afirmam a lógica da educação privatista, centrada em uma racionalidade técnica

\footnotetext{
${ }^{5}$ São tempos formativos, cujo objetivo é fortalecer o trabalho como princípio educativo na ação dos sujeitos do campo, para que a sua identidade e seu vínculo com o trabalho e com a vida continue a existir e a resistir (SILVA, 2017).
} 
e na epistemologia da prática. Como exemplos citamos a alfabetização com o método fônico e a militarização das escolas. Quanto à formação de professores destacamos: a Base Nacional Curricular para a Formação de Professores instituída pela Resolução CNE/CP № 2, de 20 de dezembro de 2019, que institui as Diretrizes Curriculares Nacionais para formação inicial de professores para Educação Básica; e a Base Nacional Comum para a Formação Inicial de Professores da Educação Básica (BNC Formação).

As normativas supramencionadas procuram controlar e regular a concepção e as práticas dos professores, alinhadas aos parâmetros dos organismos multilaterais (OM) como a Organização das Nações Unidas para Educação, a Ciência e a Cultura (Unesco), Banco Mundial (BM), Organização para a Cooperação e Desenvolvimento Econômico (OCDE), dentre outros. A influência dos OM nas políticas nacionais mencionadas provocam limitações impactantes à educação do campo, dentre as quais destacamos a precarização da formação de professores e estruturação curricular, que tendem a se direcionar pelo perfil citadino; e a precarização das condições de infraestrutura, além do quantitativo de escolas fechadas no Brasil e no Pará ${ }^{6}$, baseados no critério de oferta mínima necessária, na compreensão do Estado acerca das demandas do campo.

Deste modo, este artigo tem como objeto de investigação a política de formação dos professores do campo da Amazônia paraense e sua inter-relação com a transformação da escola do campo. O estudo é resultado das pesquisas que temos desenvolvido no Programa de Pós-Graduação em Educação e Cultura, em parceria com a Faculdade de Educação do Campo do Campus Universitário do Tocantins-Cametá, e com o Programa de Pós-Graduação em Educação, do Instituto de Ciência da Educação, ambos da Universidade Federal do Pará (UFPA).

Nosso objetivo foi analisar a política de formação dos professores do campo e sua contribuição para a construção da escola do campo como prática de resistência no território da Amazônia paraense.

Quanto às questões metodológicas, os dados seguiram os procedimentos de estudos bibliográficos, análise documental e pesquisa de campo. Os documentos

\footnotetext{
${ }^{6}$ Em todo Brasil mais de 100 mil escolas foram fechadas no período de 2000 a 2015. No Estado do Pará, foram 5.355 mil escolas do campo fechadas, sendo 4.411 escolas no campo e 944 na cidade (CENSO ESCOLAR, INEP/GEPERUAZ, 2014).
} 
analisados foram: o texto da lei de Diretrizes e Bases da Educação (9394/96); o documento do Programa Nacional de Educação do Campo (PRONACAMPO), sobretudo as indicações quanto à LEDOC; o Projeto Político de Curso (PPC) do Curso da LEDOC da Universidade Federal do Pará (UFPA) do Campus de Tocantins-Cametá. Os documentos não foram analisados em categorias, mas retirados de seus conteúdos as informações necessárias para alcance de nossos objetivos, o que será demonstrado na análise a seguir.

$\mathrm{Na}$ pesquisa de campo fizemos observação e realizamos entrevistas com seis sujeitos: um docente, a coordenação da LEDOC da UFPA do Campus do Tocantins-Cametá; um representante dos movimentos sociais e três estudantes. Suas narrativas encontram-se ao longo do texto identificadas com nomes fictícios para resguardar sua autoria e seguir os princípios éticos da pesquisa.

$\mathrm{Na}$ análise de dados, ancoramo-nos na análise de conteúdo de Bardin (2010) e Franco (2008) na perspectiva de triangularmos os dados coletados por meio dos documentos e do trabalho de campo. Em termos de interpretação, dialogamos com autores que nos possibilitam a crítica em relação à problemática anunciada, dentre os quais destacamos as contribuições clássicas de Gramsci (1989), e as contribuições de estudiosos nacionais como: Freire (2007), Caldart (2020) e Molina (2014).

Este texto se estrutura em duas partes. A primeira apresenta reflexões sobre a política de formação de professores do campo, na Amazônia paraense, e a segunda trata da experiência formativa do curso da LEDOC e suas contribuições para a construção de práticas formativas na/da Educação do Campo como espaços de resistência no território do Baixo Tocantins.

\section{A política de formação inicial dos professores do campo no cenário nacional e na Amazônia paraense}

A política de formação de professores, entre os séculos XX e XXI, tem sido um tema muito debatido nas instâncias governamentais, nas instituições de formação e em diversos setores da sociedade. Também se pode afirmar que a política de formação se constitui como pauta das exigências reivindicativas dos movimentos sociais e sindicais, sobretudo, nas associações da categoria docente. 
Quando consideramos as ações governamentais, a concepção de formação em meio às reformas implementadas tem se traduzido como um serviço na relação entre Estado e a lógica de mercado, pelo qual é atribuído um valor que se paga para ter acesso. Esta relação envolve o público e o privado, fundamentada na Lei № 11.079/2004, a qual institui normas gerais para licitação e contratação de parceria público-privada no âmbito da administração pública. Segundo Oliveira et al, (2005), consiste no princípio de que o governo busca recursos financeiros adicionais e possibilita que investidores possam construir e manter obras, e em troca ter direito de exploração comercial dos serviços.

A perspectiva legal a qual nos referimos acima se orienta através de uma lógica neoliberal, que envolve os OM por recolocar a política e a economia brasileira em um alinhamento com o desenvolvimento e crescimento econômicos sob as diretrizes do chamado Consenso de Washington. Por um conjunto de medidas formuladas por economistas na capital Norte Americana em 1989, adotou-se como princípio a liberalização econômica, que se traduzia pela diminuição do papel do Estado e por uma maior participação do mercado no processo de decisão em rápidas e eficientes questões econômicas.

As deliberações do consenso de Washington tinham como base o "ajuste fiscal, privatização, liberalização [...], desregulamentação do setor financeiro, liberação do comércio, incentivo ao investimento externo, reforma do sistema de previdência/seguridade social e reforma do mercado de trabalho" (SGUISSARDI; SILVA JR., 2001, p.27).

Quando analisamos a repercussão das políticas ultraliberais na educação, inúmeras mudanças podem ser identificadas. Freitas (2007) pondera que a partir dos anos 2000, insere-se na formação de professores cursos à distância, com a finalidade de ampliar o atendimento às demandas docentes sem qualificação em nível superior. A alternativa para isso foi a Educação a Distância (EAD), criada por meio de um aparato tecnológico com a utilização de um sistema midiático interativo, no qual se reduz a mediação pedagógica entre o professor e aluno. A mesma autora diz que assim "responsabiliza-se os estudantes, que já chegam a estes cursos, em condições desiguais frente aos demais estudantes das universidades, sem que se ofereçam as condições de ensino" (p. 1213). 
Pesquisa das Tecnologias da Informação e Comunicação (TIC-Domicílios) ${ }^{7}$ realizada pelo Centro Regional de Estudos para o Desenvolvimento da Sociedade da Informação, divulgada em agosto de 2019 , destaca que $70 \%$ da população brasileira possui acesso à internet, sendo o celular o meio mais utilizado por $97 \%$ dos usuários. Segundo a mesma pesquisa, na área urbana, 74\% tem conexão à internet, enquanto nas áreas rurais, esse número alcançou apenas 49\%. Nas camadas mais pobres de toda a população $48 \%$ estão conectados à rede, embora o número de domicílios sem acesso à conexão em todo o país seja de 46,5 milhões.

Como se viu pelas evidências supracitadas, no Brasil as desigualdades também são observadas no acesso à tecnologia de comunicação. No entanto, a política de formação a distância se estendeu à Amazônia paraense, inicialmente por meio de instituições privadas, sem aparato tecnológico necessário para desenvolver um trabalho com o mínimo de qualidade. $\mathrm{O}$ déficit de qualidade era observado facilmente porque a maioria dos cursos funcionava em escolas públicas estaduais e municipais que cediam o espaço para que ocorressem as aulas "presenciais", porém, sem ter infraestrutura tecnológica necessária.

A Lei de Diretrizes e Bases (LDB) 9.394/96 decreta no art. $87 \S 4^{\circ}$ que "Até o fim da Década da Educação somente serão admitidos professores habilitados em nível superior ou formados por treinamento em serviço". Sobre isso, Freitas (2002, p. 148) afirma que:

Os professores têm sido levados a frequentar cursos de qualidade duvidosa em grande parte, pagos por eles. [...] esse processo tem se configurado como um precário processo de certificação e/ou diplomação e não qualificação e formação docente para 0 aprimoramento das condições do exercício profissional. A formação em serviço da imensa maioria dos professores passa a ser vista como lucrativo negócio nas mãos do setor privado e não com política pública de responsabilidade do Estado e dos poderes públicos.

Assim, a partida para obter a formação inicial e continuada se dá na iniciativa privada, uma vez que a década de 1990 foi marcada pela presença de um Estado mínimo. Naquele momento já existia a ideia de iniciativa privada na educação superior como um negócio lucrativo e também como uma opção para o professor sem formação alcançar em tempo hábil a formação exigida pela lei. Por isso, os

\footnotetext{
${ }^{7}$ Pesquisa sobre uso das Tecnologias da Informação e Comunicação nos Domicílios brasileiros (TICDomicílio) 2018, publicada em 2019. Disponível em https://www.cetic.br/pesquisa/domicilios/publicacoes/ Acesso em abril de 2020
} 
professores recorreram e ainda recorrem a esses ambientes na perspectiva de adquirir a formação em nível de Graduação e Pós-Graduação (SILVA, 2011).

Os professores que se encontravam fora dos parâmetros das novas exigências de formação, buscavam a alternativa nas universidades privadas, à distância, aligeiradas e com ensino precário, pois as aulas presenciais aconteciam e acontecem sob a mediação de um tutor. Tudo isso foi destacado por Freitas (2007) ao dizer que "a maioria dos cursos de formação na modalidade à distância, no Brasil [...] se apresenta como uma forma de aligeirar e baratear a formação. [...] pensada como uma política de formação compensatória que visa suprir a oferta de cursos regulares" (p.1214).

Quanto ao financiamento público da formação de professores, as políticas de formação que têm atendido professores do campo no Brasil e na Amazônia, nas últimas décadas, articulam-se sob quatro programas, a saber: Universidade Aberta do Brasil (UAB-2006); o Plano Nacional de Formação de Professores (PARFOR2009); o Programa de Formação Superior e Licenciatura Indígena (PROLIND) e o Programa de Apoio à formação Superior em LEDOC (PROCAMPO-2009). Este último foi criado a partir das experiências piloto da LEDOC que estavam sendo desenvolvidas na Universidade de Brasília (UnB), Universidade Federal de Sergipe (UFS), Universidade Federal da Bahia (UFBA) e Universidade Federal de Minas Gerais (UFMG) desde 2007. Constituíram-se como programas gratuitos, com objetivo de formar os professores sem nível superior nos diversos territórios brasileiros.

A partir de 2006, o fluxo de oferta de cursos públicos de ensino superior, na modalidade à distância se multiplica com introjeção da UAB. A partir de então, há a intensificação da oferta de diversos cursos de formação inicial e continuada, capacitação de dirigentes, gestores e profissionais da educação. Tal incremento na oferta desacelerou os cursos de curta duração em funcionamento pela iniciativa privada.

Mesmo com tal direcionamento, a partir da UAB, as políticas continuam centradas numa formação fundamentada aos interesses mercadológicos, na visão capitalista, pela qual se prioriza a formação instrumental, sem aprofundar os conceitos e a visão de mundo que caracterizariam uma perspectiva política de formação docente. Sobre isso, Freitas (2007) destaca a continuidade da formação 
baseada nos princípios da aprendizagem dos conteúdos escolares, na avaliação dos resultados e na gestão do trabalho pedagógico.

A formação conteudista à qual nos referimos está relacionada à educação bancária, apresentada por Freire (2007). Segundo o autor, essa concepção se caracteriza em moldar, domesticar, transformar a pessoa em mero objeto a serviço da cultura dominante, elitista, conservadora, que se projetou para disseminar e se perpetuar no poder. Continuando seus argumentos Freire (2007, p. 34) diz que:

Nestas sociedades se instala uma elite que governa conforme as ordens da sociedade. Esta elite impõe-se às massas populares. Esta imposição faz com que ela esteja sobre o povo e não como povo. As elites prescrevem as determinações às massas. Estas massas estão sob o processo histórico. Sua participação na história é indireta, não deixam marcas como sujeitos, mas como objetos.

As colocações de Freire expressam uma nação, a nação brasileira, sendo manipulada pelas elites internacionais dos países ricos. Elites estas que monitoram e manipulam as políticas sociais, inclusive a educacional. Deste modo, a visão de educação homogeneizadora e disciplinar continua a fomentar o ideário não somente da formação de professores, mas todo um processo epistemológico presente na educação básica, que direta ou indiretamente torna a profissão docente um território em disputa (NÓVOA, 1995).

Mesmo nesse contexto de supremacia liberal é possível observar, no entanto, que a sociedade civil organizada, em especial atores dos movimentos sociais, resistem às reformas que se entrelaçam aos modos de produção flexível e ao estilo da classe dominante internacionalizada, que exerce o controle hegemônico do saber/poder/fazer estabelecido nas lógicas de produção do sistema capitalista nesta economia globalizada. E exigem políticas e ações públicas que atendam aos direitos mais básicos dos povos do campo. Entre esses direitos destacamos a educação, saúde, previdência, reforma agrária, trabalho, ou seja, condições dignas para continuar a existir como sujeitos do campo.

É no campo desta luta que situamos a adoção de alguns programas de formação docente. Dentre estes programas, citamos o PARFOR. De acordo com Scheibe (2010, p. 986), o PARFOR é um programa que tem o "[...] objetivo de estabelecer ações e metas para qualificação de professores brasileiros que ainda não possuem a formação considerada adequada ao trabalho que exercem". Dessa forma, se funcionar de acordo com sua prescrição, Camargo (2017, p. 133) diz que 
o programa se constitui como "[...] uma possibilidade de mudança em direção à superação das assimetrias regionais, além de contribuir (de certa forma) para a ruptura com os programas de curta duração e com o caráter mercadológico que predominava desde a LDB [...]".

Ainda sobre a relevância do PARFOR, pode-se dizer que o programa responde ao que prevê o Decreto № 6.755/2009, que institui a Política Nacional de Formação de Profissionais do Magistério da Educação Básica, que disciplina a atuação da Coordenação de Aperfeiçoamento de Pessoal de Nível Superior-CAPES no fomento a programas de formação inicial e continuada. No Art. $3^{\circ}$ inciso VII do decreto, lê-se que dentre os objetivos desta política nacional de formação se destaca a necessidade de "ampliar as oportunidades de formação para o atendimento das políticas de educação especial, alfabetização e educação de jovens e adultos, educação indígena, educação do campo e de populações em situação de risco e vulnerabilidade social" (BRASIL, 2009).

Além do PARFOR, os programas PROLIND e PROCAMPO são articulados ao Programa Nacional de Educação do Campo (PRONACAMPO), efetivado pela Portaria n. 86, de $1^{\circ}$ de fevereiro de 2013 e regulamentado pelo Decreto ํㅡ 7.352/2010 e dispõe sobre a política de educação do campo e o Programa Nacional de Educação na Reforma Agrária-PRONERA. Esses programas atendem a demandas que historicamente ficaram à margem das políticas públicas educacionais. Estes são também os programas pelos quais os indígenas e os povos do campo têm feito o enfrentamento para garantir que na formação inicial sejam reconhecidas suas identidades e seus modos de vida. Uma das mais importantes estratégias para a formação diferenciada é que a elaboração dos Projetos Pedagógicos de Cursos universitários reconheça como formativa a alternância entre tempo universidade e tempo comunidade.

A perspectiva de formação dos professores do campo nasceu especialmente com o Programa Nacional de Educação na Reforma Agrária em 1998, a partir da organização Movimento Nacional de Luta Por uma Educação do Campo. O objetivo era alfabetizar, elevar a escolaridade e ofertar cursos de nível superior aos trabalhadores assentados das áreas de reforma agrária.

A luta pelo direito a educação nos assentamentos e acampamentos da reforma agrária, tem como marco inicial a perspectiva para a construção de escola 
do campo. Para isso teve seu marco inicial no I Encontro Nacional de Educadores e Educadoras na Reforma Agrária (1996) ENERA, e na I Conferência Nacional de Educação do Campo (1998). Este marco pode ser compreendido assim porque foram nestes momentos que se apresentaram as denúncias do descaso do Poder Público para com a garantia do direito à educação e a escola nas comunidades rurais e nos assentamentos.

Os encontros nacionais mencionados foram protagonizados pelo Movimento dos Trabalhadores Sem Terra (MST). Este movimento avançou nas suas conquistas, pois enfrentou dificuldades (violência e criminalização) e pautou a reforma agrária, como o direito de viver, estudar e produzir com dignidade na terra. Daí se intensifica a mobilização coletiva para a construção de escolas nos assentamentos rurais que tivessem sintonia política e pedagógica com os princípios do movimento, isto é, para ser "conduzida pelo povo organizado e no desenho de um projeto educativo que ajude a trilhar 'o caminho transformador do sistema social'” (CALDART, 2020, p. 6)

Nesse sentido, destacamos que o MST protagonizou inicialmente a luta pela escola e, de forma articulada, foi percebendo que outros coletivos compartilhavam desta luta. Sobre isso, Caldart; Benjamin (2000) dizem que

havia muitas outras famílias trabalhadoras do campo e da cidade que também não tinham acesso a este direito. Segundo, e igualmente grave, se deram conta de que somente teriam lugar na escola se buscassem transformá-la. Foram descobrindo, aos poucos, que as escolas tradicionais não têm lugar para sujeitos como os sem terra, assim como não costumam ter lugar para outros sujeitos do campo, ou porque sua estrutura formal não permite o seu ingresso, ou porque sua pedagogia desrespeita ou desconhece sua realidade, seus saberes, sua forma de aprender a ensinar ( $p$. 45-46).

As concepções de escolas presentes ao longo do tempo, pouco consideraram a realidade construída historicamente pelas populações camponesas, suas formas de ser, produzir e resistir nos territórios urbanos e rurais. Tem-se segregado, marginalizado e criminalizado os movimentos sociais que almejam uma pedagogia diferenciada na formação crítica, e que vá ao encontro das práticas de ensino e aprendizagem dos sujeitos que têm o direito negado à escolarização.

As reivindicações pelo direito a educação não ficaram restritas somente à educação básica, pois o processo de acúmulo de luta dos movimentos sociais do campo, começaram a exigir também o acesso à educação superior pública em 
várias áreas de conhecimentos, mediadas por um currículo e projetos pedagógicos que considerassem a matriz teórica e metodológica da educação do campo.

Acreditamos que estas iniciativas, ao oferecer significativos avanços e por ofertar formação inicial e continuada aos professores das redes públicas, procura superar a concepção de racionalidade técnica e de epistemologia da prática, para assim avançar na formação de sujeitos críticos e orgânicos. A nosso ver, isso só efetivar-se-á se o processo de conscientização e de libertação dos sujeitos contribuírem para que estes professores saiam da situação de alienados, subalternos e oprimidos e se tornem sujeitos de práxis.

Como itinerário para conscientização e libertação dos sujeitos, acredita-se que a perspectiva de formação reivindicada pelos povos do campo, das águas e das florestas do Brasil e da Amazônia, apresenta-se contrária à formação centrada no mercado. A bem da verdade, a perspectiva vai ao encontro da compreensão social e educacional defendida por entidades organizadas, tais como: Associação Nacional de Política e Administração da Educação (ANPAE); Associação Nacional pela Formação de Profissionais da Educação (ANFOPE); Associação Nacional de Pós-Graduação e Pesquisa em Educação (ANPED); Confederação Nacional dos Trabalhadores em Educação (CNTE); Fórum Nacional de Diretores de Faculdades (FORUMDIR); Associação Nacional dos Docentes de Ensino Superior (ANDES) e Movimento da Educação do Campo.

Todas as entidades supramencionadas primam pela valorização da escola pública e reivindicam formação inicial e continuada indissociada da valorização profissional. A intenção é de atender a realidade dos professores, seja da cidade ou do campo, ancorados na qualidade social (SILVA, 2017).

Ao dialogar com o território da educação do campo, partimos do princípio de que formar professores para atuar em práticas educativas e pedagógicas que considerem a diversidade sociocultural dos sujeitos sociais é requerer uma epistemologia própria. Essa precisa ser representativa dos saberes, das experiências e dos modos de vida de homens e mulheres que constroem seu pertencimento social e educacional no campo, nas águas e nas florestas.

O curso de Licenciatura em Educação do Campo regulamentado a partir do Decreto 7.352/2010 e pelo PRONACAMPO é assumido pelas Universidades Federais e Institutos Federais de Educação, Ciência e Tecnologia de Ensino 
Superior. Essas instituições operam com a proposta curricular vinculada à alternância pedagógica, caracterizada por dois momentos - Tempo Universidade e Tempo Comunidade. A proposta pedagógica corrobora também para a formação em docência interdisciplinar nos anos finais do ensino fundamental e ensino médio, priorizando uma das áreas do conhecimento: linguagens e códigos, ciências humanas, ciências da natureza, matemática e ciências agrárias (EDITAL, №. 02/2012) . $^{2}$

A proposição dos cursos de licenciatura se fundamentou no contexto social dos povos do campo e quilombolas, na luta dos movimentos sociais do campo e nas necessidades de organização da educação básica presente nas comunidades rurais. A oferta dos cursos da LEDOC ocorre em 42 IES no Brasil (destes, 03 estavam naquele momento no Pará, estabelecidos a partir de 2009). A expansão ganhou maior abrangência territorial após 2013, com processo seletivo definido especificamente para sujeitos sociais de territórios camponeses, sendo a prioridade dada para professores em exercício sem graduação. No Pará houve uma expansão, pois, a LEDOC passa a ser ofertada pela UFPA (Campi de Abaetetuba, Altamira e Cametá), Universidade Federal do Sul e Sudeste do Pará (UNIFESSPA) e Instituto Federal do Pará (IFPA/Campi de Bragança, Breves, Castanhal e Marabá).

Diante do que até aqui foi dito, destacamos que a formação de professores do campo, a partir das experiências formativas do curso da LEDOC, ancora-se numa teoria do conhecimento em que a práxis concretiza-se como educativa e formativa. Esta proposta de conhecimento visa romper com a fragmentação estabelecida entre teoria e prática referendada pelo ceticismo, dogmatismo, realismo acrítico e criticismo não realista, os quais separam os saberes constitutivos da vida (NORONHA, 2010).

Consideramos que a práxis enquanto categoria e como ação, constitui-se como um dos caminhos essenciais para romper com a lógica da racionalidade técnica, da epistemologia da prática e da unilateralidade no campo da formação de professores. Assim sendo, afirmamos que a práxis se apresenta como uma das possibilidades para encontrar as vias da transformação e da emancipação. É nesse

\footnotetext{
8 Chamada Pública para seleção de Instituições Federais de Educação Superior - IFES, denominação utilizada para designar as Universidades Federais e os Institutos Federais de Educação, Ciência e Tecnologia, para criação de cursos de Licenciatura em Educação do Campo, na modalidade presencial.
} 
sentido que, a seguir, discutiremos a respeito das práticas de resistências para construção da escola do campo, sob a contribuição da LEDOC.

\section{Práticas formativas na/da Educação do Campo como espaços de resistência}

A política de formação dos professores do campo, referenciada política e pedagogicamente pela LEDOC, busca reconstruir a escola que se encontra presente nas comunidades rurais. Isso porque, em sentido amplo se pode dizer que "não basta ter escolas no campo, quer-se ajudar a construir escolas do campo, ou seja, escolas com um Projeto Político Pedagógico vinculado às causas, aos desafios, aos sonhos, à história e a cultura do povo trabalhador do campo" (KOLLING; MOLINA; NÉRY, 1999, p. 29).

O contexto de reconstrução da escola do campo requer, então, maior resistência por uma formação de professores inclusiva e com seu pilar na diversidade e nas políticas afirmativas. Por isso, a resistência precisou ser intensificada pelas lutas dos movimentos sociais do campo, como também de parcelas sociais que defendem uma política de igualdade social e educacional.

É neste sentido que o Movimento Nacional de Educação do Campo pauta outro projeto de formação e de escola do campo, articulados ao PRONERA e à LEDOC. Estas experiências formativas tiveram seus projetos pedagógicos formulados de forma coletiva a partir da matriz teórico-prática, centrado na epistemologia da práxis, construídos em sintonia com as lutas dos movimentos sociais do campo, os quais têm demandado por políticas educacionais como uma fração das políticas públicas.

As demandas se justificam, por entenderem que a defesa por outro projeto de educação do campo não está dissociada da questão agrária e da concentração fundiária no Brasil. Também devemos ressaltar que a educação do campo não nasce na academia, nem da teoria, ela nasce da realidade, da materialidade concreta das lutas dos sujeitos camponeses pelo direito à terra (MOLINA, 2014).

A LEDOC representa uma alternativa à formação dos professores e, também, um passo necessário para a construção de um trabalho interdisciplinar na universidade e nas escolas. Da mesma forma, compreende-se como a possibilidade de problematizar e construir a escola do campo; como perspectiva de garantia do 
acesso e permanência das crianças, jovens e adultos do campo; além de ser um marco para o acesso à educação superior pública aos povos do campo, os quais estiveram historicamente ausentes deste direito.

Dentre as práticas de resistência possíveis e prováveis para as mudanças necessárias na escola do campo destacamos a integração entre os conhecimentos socioculturais e científicos. A integração poderá gerar mais resistência quando provocada na interação entre a formação inicial e a realidade concreta dos sujeitos camponeses.

Com a intenção de demonstrar traços de resistência no lócus investigado, apresentamos, na sequência, depoimentos e nossas análises, tomando como base o 'olhar' dos entrevistados sobre a importância da formação oferecida pela LEDOC como espaço de práxis. Acreditamos que esse 'olhar' possa, de forma significativa, contribuir para o repensar da escola ainda rural $^{9}$, a qual atende aos povos do campo em suas comunidades e na cidade.

Em relação às práticas de resistência para construir a escola do campo, é que damos destaque para os depoimentos que expressam o quanto a formação vivenciada pela LEDOC tem apontado caminhos da mudança. Procuramos, assim, expressar o que declarou Freire (2016), que a realização da prática da liberdade é a superação da contradição opressor-oprimido, por meio do processo de conscientização de homens e mulheres do campo. É o que expressa o depoimento:

Vejo que a formação do curso de Licenciatura em Educação do Campo é bem diferenciada. Por exemplo, as disciplinas que nós estamos tendo estão dando suporte, pois tem feito a gente aprender a se identificar como pessoa do campo e identificar também as nossas raízes dentro da nossa comunidade. Isso nos leva a compreender que temos um currículo muito diferenciado, porque aprendemos a lidar com nossa realidade e a ser um educador, de fato, que venha trabalhar dentro das escolas das comunidades, levando em consideração nossas raízes e nossas culturas. Tivemos uma disciplina sobre alternância que foi de suma importância para que a gente pudesse compreender que existe os tempos

\footnotetext{
9 "A escola rural historicamente defendeu que os saberes a serem transmitidos devem ser poucos e úteis para mexer com a enxada, plantar, colher, levar para a feira [...] aprender apenas os conhecimentos necessários para sobreviver e até para modernizar um pouco a produção; introduzir novas tecnologias, sementes e adubos, etc. Essa visão utilitarista sempre justificou a escola rural pobre, os conteúdos primaríssimos, a escolinha das primeiras letras. O projeto de escola do campo tem de incorporar uma visão mais rica do conhecimento e da cultura, uma visão digna de campo, o que será possível se situarmos a educação, o conhecimento, a ciência, a tecnologia, a cultura como direito e as crianças e jovens, homens e mulheres do campo como sujeitos desses direitos" (ARROYO, 2004, p. 82).
} 
educativos, que o campo é diferenciado, que ele precisa ser entendido de acordo com sua realidade, de acordo com suas produções (Margarida dos Santos -estudante LEDOC).

Os aprendizados vivenciados no tempo/espaço formativo do curso de Licenciatura em Educação do Campo se concretizam nas possibilidades de se ampliar uma concepção de trabalhador e de escola do campo. Isso ocorre porque a formação enfatizada no depoimento revela uma disseminação do conhecimento interdisciplinar e aponta o quanto é importante a intervenção nas comunidades para se construir uma escola do campo diferenciada.

O curso parece trazer novos olhares, novos horizontes, alarga a visão de mundo e de sujeito do campo, uma visão de escola ampliada, ancorando-se no campo do devir. Tudo isto nos leva a afirmar que há um anseio para a construção de uma escola do campo e, no depoimento acima, percebemos o quanto a LEDOC pode ser o caminho para problematizar a escola rural ainda presente nas comunidades, numa perspectiva para a construção da identidade como educador do campo a partir de uma escola que se aproxime das lutas sociais e do processo cultural dos sujeitos.

A referida licenciatura garante, entre os seus princípios, a necessidade de reconhecer as particularidades dos sujeitos coletivos do campo. Por isso, subscreve em seu PPC que "a educação do campo ganhou marco legal que assegura formalmente o direito a uma educação diferenciada que respeite as especificidades, as particularidades dos sujeitos implicados aos lugares onde vive" (UFPA, 2017, p. 5).

A LEDOC se propõe, desde o seu PPC (2017), à formação do sujeito crítico e, sobretudo, à perspectiva de uma aproximação com as escolas dos territórios rurais.

Para a emergência da resistência, é de fundamental importância que os estudantes em processo de formação, possam se engajar na materialidade de uma nova organização do trabalho pedagógico, em sua efetiva atuação como educador do campo. Nesse sentido, o próximo depoimento deixa claro como os sujeitos procuram se envolver na luta pela transformação de suas ações educativas nas escolas onde atuam, compreendendo-as como um território de práxis educativa. Isto pode ser observado no discurso ora apresentado. 
Quando nós vamos para o tempo comunidade a gente passa a entender a diversidade que existe naquela determinada localidade. Pensamos que tendo um conhecimento teórico, vamos dar conta de entender os conhecimentos práticos do dia a dia dos sujeitos, mas quando começamos a fazer nossas pesquisas no tempo comunidade a gente vai vendo que as coisas não é como pensávamos. Quando me deparei com a minha pesquisa lá na localidade tive uma visão totalmente diferente da vida e dos saberes dos sujeitos - hoje tenho uma visão diferente e que eu entendo de uma forma melhor o dia a dia, a forma como se trabalha, a forma como se processa as atividades que se praticam no campo, então, vejo assim, que mudou muito a minha forma de entender nossa identidade como sujeito do campo (Maria-estudante LEDOC).

É interessante destacar que a materialidade dos princípios originários da educação do campo começa a aparecer nos discursos e na prática dos estudantes que atuam como educadores nas escolas públicas. O depoimento apresentado acima, expressa com bastante clareza o quanto o curso tem lhe ajudado a pensar sobre os ideais necessários para que venha defender o projeto político pedagógico da educação do campo.

Referendando nossas interpretações, dialogamos com Frigotto (2010, p.188) ao reiterar que "na escola, os processos educativos não podem ser inventados e, portanto, não dependem de ideias ou fórmula mágica. Dependem de um conjunto de moléculas orgânicas, pari passu com a construção da própria sociedade no conjunto das práticas sociais".

As mudanças a serem feitas em uma escola do campo devem partir do princípio de coletividade, tendo-as como práticas de resistência na constituição de estratégias político-culturais, para assim conseguir integrar os modos de vida e os saberes das comunidades. É preciso ter clareza da necessidade de uma concepção de sociedade inclusiva, cujas aproximações são com o projeto de agricultura familiar e camponesa, assim como com o protagonismo dos movimentos sociais. Sem isso, não se avança no sentido de escola do campo que se pretende construir e transformar.

Para tanto, destacamos que a formação da LEDOC deve apontar para outros significados e mudanças necessárias a serem feitas na universidade e na escola. São nesses lugares que os professores desenvolvem em sua prática uma interrelação entre os conhecimentos científicos sistematizados com os saberes vivenciados de forma cotidiana pelos povos do campo. E o que estamos falando serve tanto para a universidade como para a escola e as comunidades. 
Outro destaque está na afirmação de que por meio do processo formativo, os estudantes se percebem imersos nesta prática docente diferenciada, e assumem o compromisso político e social com uma prática engajada e em sintonia com o currículo que seja representativo de suas experiências. A construção da escola do campo se afirma "pela resistência e luta das famílias e comunidades que trabalham e vivem no campo" (CALDART, 2020, p. 7). É por isso que aspiramos à formação do sujeito político, este que produz cultura e que luta pelos seus direitos como pessoa humana engajada na incansável "batalha" pela transformação social.

Sobre a perspectiva de formação comentada acima, o depoimento seguinte reitera que:

\begin{abstract}
Apostando na formação, enfim, no conhecimento. Então era importante que a universidade pudesse, através do curso direcionado aos povos do campo, pudesse ir ajudando a preservar esses saberes, através do processo de formação. E a Licenciatura em Educação do Campo trouxe essa valorização. Por isso que acreditamos que o conhecimento educacional é a principal forma de libertar do povo do campo. (Mario-Movimento Social).
\end{abstract}

No trecho de depoimento acima transcrito, a formação é entendida no sentido de batalha das ideias e de guerra de posição (GRAMSCI, 1989). Entende-se assim pelo fato de que o poder ideológico remete à tomada de consciência das contradições sociais, econômicas, políticas e culturais diante da situação de exploração imposta pela lógica excludente do capital.

A partir da leitura gramsciana, afirmamos que a LEDOC deve assumir o compromisso com a formação de intelectuais orgânicos, para se engajarem no enfrentamento político e ideológico que o sistema lhes impõe. Mas também deve ser assumida uma posição de classe no campo do devir, na perspectiva da emancipação social e humana. Portanto, faz-se necessário formalizar as denúncias sobre as posturas antidemocráticas assumidas na direção das escolas, condições de funcionamento, ausência de transporte e alimentação escolar. Vejamos o que diz sobre isso o depoimento que se segue:

Existem muitas dificuldades de um trabalho mais coletivo, pois muitos professores não moram nas comunidades, falta de tempo, desgaste, excesso de carga horária, perseguição política [...]. Acredito que se faz necessária uma formação mais voltada para a realidade, fazendo-a dentro da comunidade, envolvendo os próprios moradores, envolvendo não só a comunidade escolar, mas todos os sujeitos da comunidade, em que o professor possa sempre relacionar com a prática junto com os alunos. Em meu ponto de 
vista, isso pode ser um caminho para pensarmos a escola do campo (Carmem-Docente LEDOC).

O trecho de depoimento aponta que a formação da LEDOC se concretiza no sentido de superar a fragmentação da teoria e da prática existente no contexto das escolas rurais. No entanto, há fatores de dificuldade, como: professor que não reside nas comunidades; dificuldades de acesso às comunidades; transporte escolar escasso e precário; excesso de carga horária e a falta de tempo para uma organização mais efetiva de seu trabalho. Isto tem impedido a execução de uma pedagogia que se construa articulada com a vida dos estudantes e sintonizada com a realidade concreta das comunidades.

A aproximação com a efetiva realidade das escolas de educação básica do campo tem uma orientação-acompanhada a partir do momento em que os estudantes têm sua inserção na escola, por meio do estágio de docência. Para essa inserção, no caso da LEDOC, no território do Baixo Tocantins, os estudantes cursam: estágio nos anos finais ensino fundamental na área de Ciências da Natureza (100h); estágio no ensino médio, precisamente em Biologia e Química (100h); e estágio na Educação de Jovens e Adultos (100). Além destas 300 horas de inserção na escola, os estudantes também cumprem 100 horas de estágio em organizações populares/comunitárias. Estes estágios se configuram como uma aproximação dos estudantes com o campo profissional (RESOLUÇÃO DE ESTÁGIO DA FECAMPO, 01/2017) e também é uma oportunidade para aprofundar a pesquisa que desenvolvem quando estão em Tempo Comunidade.

$\mathrm{Na}$ inter-relação do estágio com a pesquisa, trazemos o olhar de sujeitos entrevistados, suas críticas sobre a negação do direito à escola, e a importância da Licenciatura em Educação do Campo para denunciar as contradições das escolas rurais.

As escolas rurais nas comunidades ainda seguem um modelo multisseriado com escolas precárias e com péssimas condições de trabalho, ainda tem o ensino médio que é pelo modular, onde os professores fazem rodízio nas comunidades e passam pouco tempo nas aulas com a gente e em condições de espaço muito ruim, pois até no salão paroquial a gente estuda (José-estudante LEDOC).

No campo, a partir das visitas que fazemos nas comunidades e pelos depoimentos dos próprios alunos, há um problema seríssimo de questões políticas e eleitoreiras, pois as prefeituras só colocam para trabalhar nas escolas os professores contratados que não são das comunidades; isso causa um desânimo nos alunos que cursam 
a licenciatura em educação do campo e querem continuar nas suas comunidades para contribuir (Conceição-Coordenadora LEDOC).

Os depoimentos denunciam as precárias condições do ensino no campo. Os problemas estão presentes desde os anos iniciais, com as escolas multisseriadas, pouco pautados nas agendas do Poder Público. O descaso não tem assegurado qualidade nas condições de funcionamento das escolas em razão da metodologia que vem sendo adotada pelos professores. Ou seja, nestas turmas há um problema gravíssimo da falta de uma proposta pedagógica, como também de formação permanente dos professores.

Outra questão é o ensino médio, que tem sido atendido no estado do Pará pelo Sistema Modular de Ensino (SOME). Este funciona por módulos, porém, há muitas dificuldades para sua efetivação, uma vez que nem sempre o regime de colaboração com as prefeituras têm se estabelecido. Entre as principais dificuldades são relatados: o tempo das aulas, a ausência de professores e, sobretudo, quanto a uma estrutura para o funcionamento das aulas.

Há também a ser destacada a questão dos contratos de trabalhos temporários, que têm sido efetivados de forma alarmante nas escolas do campo. Com isto, as prefeituras não realizam concursos públicos e acabam por ter o cargo público como uma moeda de troca em processos eleitorais. Tal fato tem desmotivado os estudantes da LEDOC que se preparam para trabalhar, mas, devido às questões políticas, não conseguem atuar em seu campo profissional.

Outrossim, destacamos que os sujeitos sociais vão trabalhando sua organicidade no sentido de perceber que "as escolas precisam ajudar as famílias a entender porque é preciso mantê-las, e como escolas públicas, qual o seu lugar nos processos de 'resistência ativa' dessas comunidades" (CALDART, 2020, p. 8). Por isso que a escola do campo deve transgredir políticas curriculares urbanocêntricas, que historicamente têm sido impostas pelo poder hegemônico do capital. É dessa forma que a escola do campo poderá protagonizar práticas educativas referenciadas pelo trabalho, pela agroecologia, pela agricultura familiar e por um meio ambiente ecologicamente sustentável.

A escola do campo a ser transformada deve se constituir por sua concreticidade, para superar as contradições vivenciadas e impostas pelas condições estruturais da sociedade. É dessa forma que poderá ir ao encontro de 
práticas educativas de resistências, que vislumbrem perspectivas de outra sociedade de forma humana, e coerentes com as novas formas de sociabilidade.

A política de formação de professores do campo se vincula de forma orgânica há pelo menos 20 anos com a luta histórica do Movimento Nacional de Educação do Campo, o qual busca por meio da teoria do conhecimento, integrar a práxis. Sua iniciativa começa com a inserção dos estudantes na escola; nas organizações populares e nos movimentos de base para a realização de estudos, pesquisas e intervenções na realidade educacional. Tudo isso pode se dar a qualquer momento, mas se processa particularmente pelos estágios docentes e por processo de formação permanente e acompanhada. Tais ações visam contribuir com a construção de políticas alternativas de educação para a escola do campo na Amazônia paraense.

\section{Considerações finais}

Finalizar nem sempre é uma tarefa fácil, principalmente quando o debate deixa claras pistas de continuidade permanente enquanto o status quo do problema levantado não é alterado. Diante de situações inquietantes percebidas na realidade educacional vivenciada em comunidades do Território da Amazônia paraense, nossa pretensão foi de analisar a política de formação dos professores do campo considerando o curso de Licenciatura em Educação do Campo e as contribuições para a construção da escola do campo como prática de resistência nesse território.

Procuramos mostrar por meio de nossas fontes, como os sujeitos do campo são submetidos a iniciativas institucionais que, longe de lhes proporcionar uma ampla formação humana, coloca-os à mercê da dominação do capital, operado por ditames de Organismos Multilaterais que ditam as políticas educacionais brasileiras.

Para dar conta de nossa tarefa, utilizamos de procedimentos mistos de coleta do material empírico, os quais se constituíram de estudos bibliográficos, dados documentais e pesquisa de campo, além de um esforço pela construção de um referencial teórico de suporte. No que diz respeito aos diferentes sujeitos que colaboraram com o estudo, pudemos contar com a coordenação, docentes e estudantes do curso de Licenciatura em Educação do Campo da UFPA do Campus Universitário do Tocantins-Cametá, além de representações de movimentos sociais do campo. Todos envolvidos com o curso no território do Baixo Tocantins. 
Os resultados nos mostraram que, de fato, confirma-se a existência de ações implementadas no campo, para que a educação mantenha os sujeitos sob o jugo do capital. No entanto, os resultados revelam também que há políticas de formação direcionadas aos professores do campo, com destaque para a Licenciatura em Educação do Campo, que têm se configurado como mecanismo de resistência. Sabe-se que essas iniciativas são dirigidas por legislações que muitas vezes dificultam o avanço de uma formação comprometida com o amplo desenvolvimento das potencialidades dos sujeitos, da mesma forma que se somam às dificuldades geradas pelas condições estruturais de ausência de políticas públicas nos territórios, tais como: problemas de infraestrutura, transporte, emprego, entre outras.

Apesar das dificuldades em geral, a Licenciatura em Educação do Campo tem pautado estudos e debates que corroboram para conhecer a escola do campo, identificando as contradições, seus desafios e as possibilidades de transformações por meio da construção de práticas de lutas e resistências. Acreditamos que a luta continua, e que estamos no caminho!

\section{Referências}

ARROYO, M. G. A educação básica e o movimento social do campo. In: ARROYO, Miguel Gonzalez; CALDART, Roseli Salete; MOLINA, Mônica Castagna (Org.). Por uma educação do campo. Petrópolis, Rio de Janeiro: Vozes, 2004.

BRASIL. [Presidência da República]. Decreto № 10.252, de 20 de fevereiro de 2020. Aprova a Estrutura Regimental e o Quadro Demonstrativo dos Cargos em Comissão e das Funções de Confiança do Instituto Nacional de Colonização e Reforma Agrária - Incra, e remaneja cargos em comissão e funções de confiança. Diário Oficial da União. Brasília, 2020.

BRASIL, Ministério da Educação. Resolução CNE/CP nº 2, de 20 de dezembro de 2019. Define as Diretrizes Curriculares Nacionais para a Formação Inicial de Professores para a Educação Básica e institui a Base Nacional Comum para a Formação Inicial de Professores da Educação Básica (BNC-Formação). Diário Oficial da União. Brasília, 2020.

Plano Nacional de Educação (PNE). Lei № 13.005, de 25 de junho de 2014. Aprova o Plano Nacional de Educação- e da, outras providências. Diário Oficial da União. Brasília, 2014.

Portaria n. 86, de $1^{\circ}$ de fevereiro de 2013. Institui o Programa Nacional de Educação do Campo - PRONACAMPO. Diário Oficial da União, Brasília, 2013.

SESU/SETEC/SECADI. Edital № 02, de 31 de agosto de 2012. Chamada Pública para seleção de Instituições Federais de Educação Superior - IFES e de Institutos Federais 
de Educação, Ciência e Tecnologia - IFET, para criação de cursos de Licenciatura em Educação do Campo, na modalidade presencial. Brasília, 2012.

Decreto n. 7.352, de 04 de novembro de 2010b. Dispõe sobre a política de educação do campo e o Programa Nacional de Educação na Reforma Agrária- PRONERA. Diário Oficial da União, Brasília, 2010.

Decreto lei n. 6.755, de 29 de janeiro de 2009. Institui a Política Nacional de Formação de Profissionais do Magistério da Educação Básica, disciplina a atuação da Coordenação de Aperfeiçoamento de Pessoal de Nível Superior- CAPES no fomento a programas de formação inicial e continuada, e da, outras providências. Diário Oficial da União, Brasília, 2009.

LEI № 11.079, de 30 de dezembro de 2004. Institui normas gerais para licitação e contratação de parceria público-privada no âmbito da administração pública. Diário Oficial da União. Brasília, 2004.

Lei n. 9.394, de 20 de dezembro de 1996. Estabelece as Diretrizes e Bases da Educação Nacional. Diário Oficial da União, Brasília, DF, 23 dez. 1996.

BARDIN, L. Análise de conteúdo. Trad. Luís Antero Reto e Augusto Pinheiro. Lisboa, Edições 70, 2010.

CALDART, R. S. Aula Inaugural do semestre do curso de Licenciatura em Educação do Campo. Universidade Federal do Rio Grande do Sul, Campus Litoral, 9 de março 2020.

A escola do campo em movimento. In: BENJAMIN, César; CALDART, Roseli Salete. Projeto popular e escolas do campo. Brasília, DF: Articulação Nacional Por Uma Educação Básica do Campo, Coleção Por Uma Educação Básica do Campo, 2000.

CAMARGO, A. M. M. de. PARFOR. In: SEGENREICH, Stella Cecilia Duarte (Org.). Organização institucional e acadêmica na expansão da educação superior: Glossário. Rio de Janeiro: Publit, 2017.

Centro Regional de Estudos para o Desenvolvimento da Sociedade da Informação (Cetic.br). 2019. Disponível em https://www.cetic.br/pesquisa/domicilios/. Acesso em abril de 2020.

FRANCO, M. L. P. B. Análise de Conteúdo. 3. ed. Brasília: Liber Livro, 2008.

FREIRE, P.. Pedagogia do Oprimido.53. ed. Rio de Janeiro: Paz e Terra, 2016.

Educação e mudança. São Paulo: Editora paz e terra, 2007.

FREITAS, H. C. L. de. A (nova) política de formação de professores: A prioridade postergada. Revista Educação e Sociedade. Campinas, vol. 28, n. 100 - Especial, p. 12031230, out. 2007.

Formação de professores no Brasil: 10 anos de embate entre projetos de formação. Revista Educação e Sociedade. Campinas, vol. 23, n. 80, set. 2002.

FRIGOTTO, G. Educação e a crise do capitalismo real. 6. ed. São Paulo: Cortez, 2010. 
GRAMSCI, A. Os Intelectuais e a Organização da cultura. 7.ed. Rio de Janeiro: Civilização Brasileira, 1989.

GRUPO DE ESTUDOS E PESQUISAS EM EDUCAÇÃO DO CAMPO DA AMAZÔNIA (GEPERUAZ). Banco de dados, 2014.

HAGE, S. A. M.; SILVA, H. do S. de A.; SOUZA, D. D. L. de. Movimentos sociais do campo e educação na Amazônia: as lutas e resistências num cenário de negação de direitos. 39a Reunião Nacional da ANPEd. GT03 - Movimentos Sociais, Sujeitos e Processos Educativos, Niterói-RJ, 2019.

INSTITUTO NACIONAL DE ESTUDOS E PESQUISAS EDUCACIONAIS (INEP) Anísio Teixeira. Sinopse estatísticas da educação básica 2014. [online]. Brasília, Inep, 2014.

MANCEBO, D. Políticas, Gestão e Direito à Educação Superior: novos modos de regulação e tendências em construção. In: MOLINA, Mônica Castagna; HAGE, Salomão Mufarrej (Org.). Licenciaturas em Educação no Campo: resultados da pesquisa sobre os riscos e potencialidades de sua expansão. 1. ed. Florianópolis: LANTEC/CED/UFSC, 2019.

MOLINA, M. C; NÉRY, I.; KOLLING, J. E. Por uma educação básica do campo (Org.). 1999.

MOLINA, M. C. Desafios da Licenciatura na materialização das escolas do campo. Palestra. IV Seminário Nacional das Licenciaturas em Educação do Campo. Belém, 2014.

NORONHA, O. M.. Epistemologia, formação de professores e práxis educativa transformadora. Quaestio. Sorocaba, SP, v. 12, p. 5-24, jul, 2010.

NÓVOA, A. O passado e o presente dos professores. In: NÓVOA, A. Profissão Professor. Porto, Porto Editora, 1995.

OLIVEIRA, J. F. de; CATANI, A. M. A reconfiguração do campo universitário no Brasil: conceitos, atores, estratégias e ações. In: OLIVEIRA, J. F. (Org.). O campo universitário no Brasil: Políticas, ações e processos de reconfiguração. Campinas, SP: Mercado das Letras, 2011.

OLIVEIRA J. F. de; DOURADO, L. F.; VELOSO, T. C. M. A; SOUSA, A. M. G. A reforma da educação superior e os mecanismos de parceria público-privado. Perspectiva, Florianópolis, v. 23, n.02, p.323-348, jul-dez, 2005.

RESOLUÇÃO DE ESTÁGIO 01, de 2017. Define procedimentos para a realização do Estágio Docente no Curso de Licenciatura em Educação do Campo, na FECAMPO, no Campus Universitário do Tocantins-Cametá da Universidade Federal do Pará, 2017.

SILVA, H. do S. de A. S. Política de formação de educadores do campo e a construção da contra-hegemonia via epistemologia da práxis: análise da experiência da LEDOCUFPA-Cametá. 2017. 306 f. Tese de Doutorado (Programa de Pós-Graduação em Educação) Instituto de Ciência da Educação-UFPA, Belém, 2017.

Programa Escola Ativa: política de formação continuada de professores de escolas multisseriadas e seus impactos no cotidiano da sala de aula. 2011. 202 f. Dissertação (Programa de Pós-Graduação em Educação). Universidade do Estado do Pará, Belém, 2011. 